\title{
Risk Synchronization in International Stock Markets
}

\author{
Helena Chuliá ${ }^{\mathrm{a}}$
}

\author{
Andrés D. Pinchao ${ }^{\mathrm{b}} \quad$ Jorge M. Uribe ${ }^{\mathrm{c}}$
}

\begin{abstract}
We explore international risk synchronization in global stock markets over the last two decades. To this end, we construct global indices of risk synchronization based on individual estimations of market risk and their aggregation via spatial correlations. We then use these indices to analyse the effects of several financial crises on market risk synchronization. Our results reveal different risk-profile dynamics for mature and emerging markets. Contrary to general reports, we also find that not all financial crises induce a higher level of synchronization among markets, at least in relative terms. Indeed, some crises had the opposite effect, that is, a decoupling of market risk.
\end{abstract}

Keywords: risk propagation, synchronization, stock market crises, international markets, spatial correlation

JEL Classification: C43, E44, G15, F36.

This work was supported by the Spanish Ministry of Economy under grants ECO201566314-R and ECO2016-76203-C2-2-P.

a Corresponding author: Riskcenter and Department of Econometrics, University of Barcelona, Av. Diagonal, 690, 08034, Barcelona, Spain. E-mail: hchulia@ub.edu.

b Central Bank of Colombia and Universidad del Valle, Cali, Colombia. E-mail: andres.pinchao@correounivalle.edu.co.

c Riskcenter and Department of Economics, Universidad del Valle, Cali, Colombia. E-mail: jorge.uribe@correounivalle.edu.co. 


\section{Introduction}

In recent times, and with increasing frequency, financial markets and the real economy have been shaken by shocks of substantial magnitude, occurring at unpaired locations (emerging and developed countries). The effects of these shocks have not been restricted within the borders of a single country nor have they left unaffected the real side of the markets to which they propagate. Ultimately, when sufficiently strong, these shocks have resulted in global recessive episodes, such as the Great Recession, and have ended up undermining global economic welfare in an unparalleled fashion.

As a result, the financial literature on financial market linkages has experienced a remarkable boom over the last few decades. The focus of the early literature was on providing analyses of the impact of international cross-spillovers on the mean and/or variance of stock market returns (see King and Wadhwani, 1990; Bae and Karolyi, 1994; King et al., 1994; Koutmos and Booth, 1995; Karolyi and Stulz, 1996; Ng, 2000; Worthington and Higgs, 2004; and Baele, 2005, among others). A further strand of the literature has explored the level of integration of financial markets (see Bekaert and Harvey, 2005; Brooks and Del Negro, 2002; Fratzscher, 2002; Hardouvelis et al., 2006; Carrieri et al., 2007; and Bekaert et al., 2013, among others). Finally, many authors have sought to analyze contagion across financial markets and to identify its fundamental causes (see Forbes and Rigobon, 2002; Pericoli and Sbracia, 2003; Corsetti et al., 2005; Mendoza and Quadrini, 2010; Aloui et al., 2011; and Baur, 2012, among others).

In this paper, we are also concerned with stock market linkages but we adopt a different perspective and undertake an empirical analysis of international risk synchronization in global stock markets between 1995 and 2015. Our aim is to provide a daily index of risk synchronization that can be used both by regulators and policymakers to monitor financial risk in the global economy as well as by practitioners as a tool for portfolio management.

Unlike the aforementioned studies, we do not estimate direct interactions between stock market returns or volatilities; instead, we construct an index of risk synchronization based on individual estimations of market risk and their aggregation using spatial econometric techniques. The importance of considering measures of 'distance', either geographical or 
economic, when attempting to understand different dimensions of stock market risk has been highlighted by several previous studies, including Pirinsky and Wang (2006), Barker and Loughran (2007), Arnold et al. (2011), Eckel et al. (2011) and Asgharian et al. (2013), among others. These authors generally aim to identify the way in which geographical, economic and financial linkages between countries influence co-movements between their market returns ${ }^{1}$.

To illustrate our approach, Figure 1 maps the Value at Risk (VaR), at the 99\% confidence level, corresponding to each market in a sample of 45 developed and emerging markets on three different dates. The VaRs are recorded in relative terms within each country. That is, we first calculate the daily univariate series of VaRs for each country from January 2, 1995 to July 23, 2015, and we then rescale each VaR into the interval $[0,1]$. This rescaling allows us to visualize relative risk, which is more important in terms of synchronization and real diversification opportunities, as opposed to absolute risk, which is essential for determining the size of a potential loss in a particular market. We consider VaRs in three different categories: low risk $\left(0-33^{\text {rd }}\right.$ percentiles $)$, medium risk $\left(33^{\text {rd }}-66^{\text {th }}\right.$ percentiles $)$ and high risk $\left(66^{\text {th }}-100^{\text {th }}\right.$ percentiles $)$ levels.

Figure 1 shows risk profiles in the global stock markets on three different dates. On both December 12, 1995 [Figure 1(a)] and April 23, 2013 [Figure 1(b)], the markets exhibited considerable risk synchronization, presenting similar relative VaRs. On April 23, 2013, global markets were largely synchronized at a high risk level; that is, they simultaneously faced high VaRs relative to their own history. In contrast, on December 12, 1995, the markets faced moderate VaRs, with considerably lower levels of associated risk. Finally, on September 23, 2008, the degree of risk synchronization was considerably lower than that displayed on the two other dates, with some markets, such as Canada and Argentina, presenting relatively low VaRs, and others, such as the US and France, presenting relatively high VaRs. In other words, different risk patterns were prevalent around the world on this specific date.

\footnotetext{
1 Other studies that have used spatial-statistical methods in addressing contagion and interdependence among markets include, for the European case, Novo (2003), Fernández-Avilés et al. (2012), and Keiler and Eder (2013), who estimate spatial autoregressive (SAR) models.
} 
[Insert Figure 1 about here]

The main contribution of our paper is to devise an index that encapsulates in one single statistic information about global risk synchronization. This is achieved using spatial crosscorrelations to aggregate individual risk profiles. In so doing, we are able to take into account the economic (or, alternatively, the geographical) distance of the markets within the sample. In addition, we also examine the effects of several financial crises on the degree of risk synchronization.

Our results reveal the different risk-profile dynamics of mature and emerging markets. Moreover, and contrary to what is generally reported, we also find that not all financial crises induce a higher level of synchronization among markets, at least in relative terms. Indeed, some crises had the opposite effect, that is, a decoupling of market risk.

The rest of this paper is organized as follows. In section 2, we present our methodology for constructing the indices of risk synchronization. In section 3, we describe our global indices and characterize different episodes of crisis, seeking to analyze their effects in terms of risk synchronization. Finally, in section 4, we conclude and present the limitations of the study and its future extensions.

\section{Data}

We use MSCI daily stock price indices, as calculated by Morgan Stanley, between January 2, 1995 and July 23, 2015 (5,363 observations per country). All data were obtained from Datastream International. The period is selected primarily on the basis of data availability. The price indices are constructed in a standard fashion for each country, which allows cross-market comparisons. We transform the original prices into logarithmic returns by taking natural logs and differentiating them. In Table 1, we report the 45 countries, including both developed and emerging economies, used in our estimations.

\section{[Insert Table 1 about here]}

The data needed to calculate spatial autocorrelations between the countries were obtained from the International Monetary Fund's webpage, specifically from the Direction of Trade 
Statistics. These data comprise values of annual bilateral trade statistics (exports and imports) between the countries in our sample, all in current USD, for the same period, 1995-2015.

The period analyzed was marked by several crises in the global financial markets, including the Asian crisis in 1997, the Russian crisis in 1998, the dotcom crisis in the US in 2000, the September 11 terrorist attacks, the global financial crisis from 2007 to 2009, and the European debt crisis in 2010, among others.

\section{Methodology}

Our proposed methodology comprises two steps. First, we estimate relative risk measures for each market in our sample. We estimate standard VaR statistics using CAViaR models, as proposed by Engle and Manganelli (2004). The first part of the methodology can be considered as an attempt to capture the 'time dimension' of market risk. Before proceeding, we rescale the VaR series to obtain relative market risk as opposed to absolute values.

In the second step, we estimate the spatial correlation patterns that occur between our estimated time statistics of risk. We do this by means of a Moran's statistic calculated for each period. This value enables us to construct a dynamic index of risk synchronization based on either geographical or economic considerations.

\subsection{Value at Risk and Quantile Autoregressions}

VaR is a method for quantifying a portfolio's market risk exposure, in our case, that of the national market. It is the maximum expected loss (or the worst loss) that might be observed during a specific period of time, under a certain level of confidence, as a consequence of holding a fixed portfolio of financial assets. One minus the specified confidence level determines the probability that a greater lost might be observed in that period (Dowd, 2005; Christoffersen, 2012).

VaR may also be understood as a quantile of the distribution of losses and, therefore, it can be calculated using a direct estimation of the quantile autoregression, as proposed by Engle and Manganelli (2004). These authors argue that, in general, the VaR can be estimated as 


$$
\operatorname{VaR}_{t}(\theta)=q_{\theta, t}=\beta_{0}+\sum_{i=1}^{r} \beta_{i} q_{\theta, t-i}+\sum_{j=1}^{q} \beta_{j} I(\cdot)
$$

where $\theta$ is the confidence level of the VaR, corresponding to the $\theta^{\text {th }}$ percentile of the returns distribution. $\left\{\beta_{0}, \beta_{i}, \beta_{j}\right\}$ are unknown parameters that must be estimated, $\sum_{i=1}^{r} \beta_{i} q_{\theta, t-i}$ is an autoregressive term that allows smooth dynamics in the estimated quantile series, and $I(\cdot)$ is an indicator function that can be associated with different sets of variables and alternative functional forms. Here, we use the symmetric absolute value specification, proposed by Engle and Manganelli (2004), which consists of defining $I(\cdot)$ as $\left|R_{t-1}\right|$, where $R_{t-1}$ are the lagged returns of the stock market index, and $|\cdot|$ is the absolute value function. We use one lag in our empirical specification, as performed, for example, in White et al. (2015).

Parameter estimation is carried out using standard quantile regression techniques, as proposed by Koenker and Bassett (1978). Quantile regression models are known to be robust to outliers, which is especially convenient when working with financial time series. These models are also semi-parametric in nature and, therefore, require minimal distributional assumptions on the underlying data-generating process. Since Koenker and Basset's seminal contribution, quantile models have attracted growing interest in many fields of economics, being used in disciplines that range from finance and macroeconomics to labor economics (Koenker, 2005). Quantile regression allows researchers to study the relationship between economic variables not only at the center but also across the entire conditional distribution of the dependent variable and, therefore, it has become an important tool in finance for directly addressing the estimation of tail-risk functions such as VaR.

\subsection{Global Market Risk Statistics}

Moran (1950) introduced the first measure of spatial autocorrelation in the literature. This measure can be used to study stochastic phenomena that are distributed in two or more spatial dimensions. It is analogous to the conventional correlation coefficient because its numerator is a product moment term (Sokal and Oden, 1978). Consequently, the value of Moran's Index ranges from +1 , a clustered, perfect positive spatial correlation, to -1 , a 
dispersed, perfect negative spatial correlation (see Figure 2). The statistic is designed as a measure of spatial autocorrelation of ordinal, interval, or ratio data and is given by

$$
\mathfrak{J}=\frac{n}{\sum_{i=1}^{n} \sum_{j=1}^{n} w_{i j}} \frac{\sum_{i=1}^{n} \sum_{j=1}^{n} w_{i j}\left(y_{i}-\bar{y}\right)\left(y_{j}-\bar{y}\right)}{\sum_{j=1}^{n}\left(y_{j}-\bar{y}\right)^{2}},
$$

where $w_{i j}$ is a weight matrix that can be calculated as the Euclidean distance between the centroids of two countries, when we are interested in the geographical distance separating the units of study. Alternatively, however, it can be constructed using economic variables, which measure economic proximity between two given units. $y_{i}$ is the specific value of the variable for each country; in our case, it represents the risk variable (rescaled VaR) for each stock market. Therefore, $y_{i}=\overline{\operatorname{VaR}}_{\mathrm{i}}^{99 \%}$ with $i=1, \ldots . N$ (number of markets in our sample) and for a given $t^{2}$. Notice that we calculate the spatial autocorrelation using the rescaled version of the $\mathrm{VaRs}$ and, therefore, $\overline{\mathrm{VaR}}_{\mathrm{i}}^{99 \%} \in[0,1]$. The rescaling is conducted by treating the series of VaRs for each country as a stochastic process and using its empirical cumulative distribution function to map the VaR into the interval $[0,1]$.

[Insert Figure 2 about here]

One specific advantage of aggregating relative risk measures into one single index by means of spatial correlation is that it allows us to introduce the economic distance between the units when constructing our index of global market risk. Controlling for economic distance in this way enables us to focus on the financial interdependence that emerges during episodes of stress or during periods of stock market booms and rallies. This strategy isolates changes in the interdependence between the markets due to other sources of variation, such as changes in commercial bilateral patterns between two given countries, during the sample period.

Nevertheless, there are several ways of introducing economic distance between countries. Here, we focus on bilateral trade because it has been identified in the previous literature as a key channel for the transmission of shocks across international markets, supported on fundamentals. In this respect, see, for example, the previously mentioned study by Arnold

$2 \mathrm{t}$ has been dropped to simplify notation. 
et al. (2011), traditional studies of contagion and market interdependence by Gerlach and Smets (1995) and Corsetti et al. (2000), and the complete review undertaken by Rigobon (2002).

Hence, as far as our results are concerned, variable $w_{i j}$ in equation 2 has two alternative definitions. First, in terms of economic distance, it can be calculated as the ratio between the sum of exports and imports of country $i$ with respect to country $j$ over the total exports and imports of country $i$ during the same year. The second definition of $w_{i j}$ corresponds to the traditional geographical weighting matrix. In this case, we calculate the Euclidian distances between the centroids of each pair of countries in our sample. Overall, we provide two indices of global risk synchronization: the first based on economic distance $\left(\mathfrak{J}_{t}^{e}\right)$ and the second on geographical or physical distance $\left(\mathfrak{I}_{t}^{g}\right)$.

\section{Results and Discussion}

In this section, we show the main results of our study. First, we present country-specific market risk statistics (i.e., daily VaRs at the $99 \%$ confidence level). Then, we show the estimated global indices of risk synchronization in stock markets, based on both economic and geographical distances. Finally, we perform recursive estimations, testing for structural breaks in the indices' dynamics, and estimate regressions with dummy variables to explore the effects of different episodes of financial crisis on the synchronization of risk.

\subsection{Country-specific Risk}

Figure 3(a) shows the dynamics of the estimated VaRs for developed markets, while Figure 3(b) presents the risk dynamics for emerging markets. We present the median and the $5^{\text {th }}$ and $95^{\text {th }}$ percentiles in each subsample. As observed, VaR dynamics, both in the median and in the extreme quantiles, reflect well-known features of risk in international stock markets in recent times. For example, in emerging markets, there was an increase in the VaR during the turmoil at the end of the twentieth and at the beginning of the twenty-first centuries. During those years, the world witnessed episodes such as the Asian crisis (1997), the Russian crisis (1999) and the Argentinean crisis (2001), affecting above all emerging economies. In the case of the developed world [Figure 3(a)], these episodes were not as 
relevant as they were for the emerging countries. In contrast, developed markets were severely affected by episodes of extreme volatility during the recent European debt crisis (2010), the aftermath of the subprime crisis (2009-2010), and the dotcom crisis (20002001).

[Insert Figure 3 about here]

Figure 4 presents a different perspective on the differences and similarities in terms of risk in the international markets. In this figure, we once again plot the median and the $95^{\text {th }}$ and $5^{\text {th }}$ empirical quantiles of VaRs in our sample, but here we use the full sample of 45 countries in constructing it. Here, the contrast between the $5^{\text {th }}$ and the $95^{\text {th }}$ percentiles is notable. While the $95^{\text {th }}$ percentile is seen to be highly volatile, with marked peaks appearing during each of the major crises over the last 20 years, the $5^{\text {th }}$ percentile can be seen to have evolved in a much smoother fashion. In other words, there are always markets in the sample that were not particularly affected by a specific crisis, regardless of its impact on the global economy in terms of monetary losses and reversals of volume and market capitalization.

[Insert Figure 4 about here]

Figures 3 and 4 show VaRs in percentages. It should be evident that there are some markets in our sample that are almost always more volatile than others. As such, relative risk may differ from absolute risk in a given set of markets and for a given period. For example, if we plot the evolution of the VaR statistics for the US market against the corresponding evolution for the Chinese market, the differences are more than evident (Figure 5). The VaR of the Chinese MSCI index is more volatile than that of the USA MSCI index, even when using standard and comparable methodologies to construct the indices. This might reflect different levels of size, liquidity and efficiency and, perhaps, different levels of international financial market integration.

However, in our analysis of risk synchronization, we are interested in relative rather than absolute risk. That is, we are not concerned about how risky a given market is compared to another; rather our interest lies in knowing how risky a market is relative to its own history. 
Thus, for us, a situation in which a set of regional markets has experienced an increment in their relative risk (or, conversely, a simultaneously decrease in relative risk) is a situation of global risk synchronization. For this reason, we map the risk statistics into the interval $[0,1]$ using the empirical cumulative function, as explained in the methodology. The resulting rescaled VaRs are more appropriate for visualizing risk synchronization (see Figure 1).

[Insert Figure 5 about here]

\subsection{Market Risk Synchronization}

\subsubsection{A Global Index of Risk Synchronization}

In Figure 6, we present two versions of our global indices of risk synchronization, based on economic and geographical measures. The figure plotted also highlights the crisis dates, in keeping with the chronologies provided by NBER, IMF, Federal Reserve Bank of St. Louis (2009) and BIS (2009) (see Baur, 2012 and Dimitriou et al., 2013). The lack of a temporal trend and high variability characterize the two indices across the whole period. Visual inspection provides no evidence of a clear pattern of correlation between the two indices and the crisis dates. What this exploratory inspection suggests is that risk synchronization is affected by the high variability characterizing financial time series, and that it responds consistently to market shocks over short periods of time but not over longer phases.

\section{[Insert Figure 6 about here]}

Although visual inspection allows us to identify a large number of positive peaks in the indices during the subprime and the European debt crises and prior to the Asian crisis, below we perform a formal analysis of the effects of the different financial crises.

\subsubsection{Summary Statistics and Evolution of Risk}

In seeking to identify structural breaks in the unconditional mean of the indices' datagenerating processes, we follow the methodology proposed by Bai and Perron (2002) for 
detecting multiple breaks in a series. That is, we look for structural breaks in parameter $\alpha_{0}$ of the following regression:

$$
\mathfrak{J}_{t}^{e}=\alpha_{0}+\varepsilon_{t}
$$

where $\mathfrak{J}_{t}^{e}$ is the global risk synchronization index, and $\varepsilon_{t}$ is a white noise term.

[Insert Table 2 about here]

Table 2 shows that the number of structural breaks in the unconditional mean of the data generating process (DGP) describing each index is between 1 and 2. Descriptive statistics for each of the periods defined by the structural changes are provided in Table 3 . In general, it seems that there was a change in the DGP of the indices in approximately 2011 (in the aftermath of the global financial crisis) and also in the transition between the twentieth and twenty-first centuries.

[Insert Table 3 about here]

\subsubsection{Synchronization and Crises}

Finally, we construct dummy variables for each crisis in our sample, and we regress the global index based on economic criteria against indicator-crisis variables and a constant. In this section, we only examine the economic index, because its interpretation is more theoretically grounded compared to that based upon geographic considerations. We report the results of this regression in Table 4.

[Insert Table 4 about here]

Based on the above coefficients and standard errors, we observe distinct effects in terms of global stock market risk synchronization of the four major crises in the last couple of decades. For example, while the Euro crisis increased the degree of risk synchronization in the global markets, the dotcom and the Asian crises did not show a statistically significant effect. More importantly, our results suggest that the subprime crisis produced a distinct effect, arguably increasing synchronization in some places, such as the North American 
markets and among their commercial allies, but at the same time opening up a gap with other markets, most notably the emerging markets of Asia and Latin America. Such features are novel to the literature. Our methodology allows us to focus directly on the synchronization produced by each crisis, taking into account at the same time the economic distance between the markets.

From the findings reported above, several conjectures can be made. While the dotcom and Euro crises were accompanied by generalized negative shocks, which impacted most of the countries in the sample (bankruptcies and mergers of technology companies in the case of the former; the bursting of real estate bubbles and sovereign debt defaults in that of the latter), the subprime crisis was characterized by differentiated market shocks. These shocks did not affect all the markets to the same degree and led the global financial system to a situation of risk decoupling. Although this evidence is new to the literature and may contradict common intuition about the relationship between risk and crises, decoupling processes following the subprime crisis have been discussed elsewhere. For instance, Dooley and Hutchison (2009) and Dimitriou et al. (2013) claim that before the crisis, several emerging countries had modified their international reserves and asset composition, including a reduction of their net public debt and lower exposure to international currencies. At the same time, these emerging economies presented surpluses in their fiscal and current accounts. Such situations may have made emerging markets more resilient than developed markets to the crisis. The latter, which enjoyed deeper and more liquid derivative markets, were also more obscure and faced greater complexities. This made these markets more difficult to monitor, resulting in a more vulnerable predisposition to the crisis.

\section{Conclusions}

We study the risk synchronization between international stock markets in a sample of 45 countries over the last couple of decades. To this end, we first construct univariate statistics of risk (VaRs) for each country in our sample from January 1995 to July 2015. We find evidence of different risk-profile dynamics in our sample when comparing mature and emerging markets. Thus, international financial crises have very different effects on the 
market dynamics of these two groups of markets. This is evident from an analysis of the $5^{\text {th }}$ and $95^{\text {th }}$ percentiles of our daily sample of estimated VaRs at the $99 \%$ confidence limit.

This analysis is further enriched with the construction of global indices of risk synchronization, based on economic and geographical considerations. The indices allow us to test various hypotheses about the effects of four major crises (namely, the Asian crisis, the dotcom crisis, the subprime crisis and the European debt crisis) in terms of market risk sychronization. We find that, while the European debt crisis, indeed, seems to have fostered the appearance of a considerable degree of risk synchronization (all markets simultaneously presented similar levels of relative risk, taking into account their economic proximity), the subprime crisis was followed by risk decoupling in the markets. The Asian crisis and the dotcom crisis did not significantly affect the degree of risk synchronization of global markets in one direction or the other.

Our findings have a number of implications for economic policy, in general, and international risk-diversification strategies, in particular. Thus, it would appear to be feasible to hedge effectively against a crisis producing a decoupling of risk by means of international portfolio diversification; however, it appears more difficult to address crises that produce a higher degree of risk synchronization. In the latter instance, it is necessary to resort to alternatives beyond the stock market.

Finally, although we identify certain patterns of risk synchronization during the major financial crises, we do not detect any clear trend in synchronization over the last couple of decades when analyzing the sample moments of the distribution of our statistics. 


\section{References}

Aloui, R., Aïssa, M.S.B., and Nguyen, D.K., 2011. Global Financial Crisis, Extreme Interdependences, and Contagion Effects: The Role of Economic Structure? Journal of Banking \& Finance, 5, 130-141.

Arnold, M., Stahlberg, S., and Wied, D., 2011. Modeling different kinds of spatial dependence in stock returns. Empirical Economics, 44, 761-774.

Arouri, M.E.H., Jouini, J., and Nguyen, D.K., 2011. Volatility spillovers between oil prices and stock sector returns: implications for portfolio management. Journal of International Money and Finance, 30, 1387-1405.

Asgharian, H., Hess, W., and Liu, L., 2013. A spatial analysis of international stock market linkages. Journal of Banking \& Finance, 37, 4738-4754.

Bae, K.H., and Karolyi, G.A., 1994. Good News, Bad News and International Spillovers of Stock Returns between Japan and the US. Pacific-Basin Finance Journal, 2, 405-438.

Bae, J., Kim, C.J., and Nelson, C., 2007. Why are stock returns and volatility negatively correlated? Journal of Empirical Finance, 14, 41-58.

Baele, L., 2005. Volatility spillover effects in European equity markets. Journal of Financial and Quantitative Analysis, 40, 373-401.

Bai, J., and Perron, P., 2002. Computation and Analysis of Multiple Structural Change Models. Journal of Applied Econometrics, 18, 1-22.

Bank for International Settlements. 2009. August. The International Financial Crisis: Timeline, Impact and Policy Responses in Asia and the Pacific. Bank for International Settlements.

Barker, D., and Loughran, T., 2007. The Geography of S\&P 500 Stock Returns. Journal of Behavioral Finance, 8, 177-190. 
Baur, D. G., 2012. Financial contagion and the real economy. Journal of Banking and Finance, 36, 2680-2698.

Beirne, J., Caporale, G.M., Schulze-Ghattas, M., and Spagnolo, N., 2010. Global and regional spillovers in emerging stock markets. A multivariate GARCH-in-mean analysis. Emerging Markets Review, 11, 250-260.

Bekaert, G., Ehrmann, M., Fratzscher, M., and Mehl, A., 2014. The global crisis and equity market contagion. The Journal of Finance, 69, 2597-2649.

Bekaert, G., and Harvey, C.R.. 1995. Time-varying world market integration. Journal of Finance, 50, 403-444.

Bekaert, G., Harvey, C.R., Lundblad, C.T., and Siegel, S., 2013. The European Union, the euro, and equity market integration. Journal of Financial Economics, 109, 583-603.

Bekaert G., Hodrick, R.J., and Zhang, X., 2009. International stock return comovements. The Journal of Finance, 64, 2591-2626.

Brooks, R., and Del Negro, M., 2002. The rise in comovement across national stock markets: market integration or IT bubble? Journal of Empirical Finance, 11, 659-680.

Carrieri, F., Errunza, V., and Hogan, K., 2007. Characterizing world market integration through time. Journal of Financial and Quantitative Analysis, 42, 915-940.

Christoffersen, P.F., 2012. Elements of Financial Risk Management. Second Edition. Waltham: Elsevier.

Corsetti, G., Pericoli, M., and Sbracia, M., 2005. Some Contagion, Some Interdependence: More Pitfalls in Tests of Financial Contagion. Journal of International Money and Finance, 24, 1177-1199.

Corsetti, G., Pesenti, P., Roubini, N., and Tille, C., 2000. Competitive Devaluations: Toward a Welfare-Based Approach. Journal of International Economics, 51, 217-41. 
Diebold F., and Yilmaz, Y., 2009. Measuring financial asset return and volatility spillovers, with application to global equity markets. Economic Journal, 119, 158-171.

Dimitriou, D., Kenourgios, D., and Simos, T., 2013. Global financial crisis and emerging stock market contagion: a multivariate FIAPARCH-DCC approach. International Review of Financial Analysis, 30, 46-56.

Dooley, M., and Hutchison, M., 2009. Transmission of the U.S. subprime crisis to emerging markets: evidence on the decoupling-recoupling hypothesis. The Journal of International Money and Finance, 28, 1331-1349.

Dowd, K., 2005. Measuring Market Risk. Second Edition. Chichester and New York: John Wiley and Sons.

Eckel, S., Löffler, G., Maurer, A., and Schmidt, V., 2011. Measuring the effects of geographical distance on stock market correlation. Journal of Empirical Finance, 18, 237-247.

Ehrmann, M., Fratzscher, M., and Rigobon, R., 2011. Stocks, bonds, money markets and exchange rates: measuring international financial transmission. Journal of Applied of Economics, 26, 948-974.

Engle, R.F., and Manganelli, S., 2004. CAViaR: Conditional autoregressive Value at Risk by regression quantiles. Journal of Business \& Economic Statistics, 22, 367-381.

Federal Reserve Bank of St. Louis. 2009. The Financial Crisis: A Timeline of Events and Policy Actions. http://timeline.stlouisfed.org

Fernández-Avilés, G., Montero, J.M., and Orlov, A.G., 2012. Spatial modeling of stock market comovements. Finance Research Letters, 9, 202-212.

Fernandez, V., 2011. Spatial linkages in international financial markets. Quantitative Finance, 11, 237-245. 
Forbes, K.J., and Rigobon, R., 2002. No contagion, only interdependence: measuring stock market comovements. Journal of Finance, 57, 2223-2261.

Fratzscher, M., 2002. Financial market integration in Europe: on the effects of EMU on stock markets. International Journal of Finance and Economics, 7, 165-193.

Gerlach, S., and Smets, F., 1995. Contagious Speculative Attacks. European Journal of Political Economy, 11, 45-63.

Hardouvelis, G., Malliaropulos, D., and Priestley, R., 2006. EMU and European stock market integration. Journal of Business, 79, 365-392.

Karolyi, G.A., and Stulz, R.M., 1996. Why do markets move together? An investigation of US-Japan stock return comovements. The Journal of Finance, 51, 951-986.

Keiler, S., and Eder, A., 2013. CDS spreads and systemic risk: A spatial econometric approach. Discussion Papers 01/2013, Deutsche Bundesbank, Research Centre.

King, M., Sentana, E., and Wadhwani, S., 1994. Volatility and links between national stock markets. Econometrica, 62, 901-933.

King, M., and Wadhwani, S., 1990. Transmission of Volatility between Stock Markets. Review of Financial Studies, 3, 5-33.

Koenker, R., and Bassett, G., 1978. Regression quantiles. Econometrica, 46, 33-50.

Koenker, R., 2005. Quantile Regression. Cambridge University Press: Cambridge.

Koutmos, G., and Booth, G., 1995. Asymmetric volatility transmission in international stock markets. Journal of International Money and Finance, 14, 747-762.

Lee, Y., 2013. Global and regional range-based volatility spillover effects. Emerging Markets Review, 14, 1-10. 
Mendoza, E.G., and Quadrini, V., 2010. Financial globalization, financial crisis and contagion. Journal of Monetary Economics, 57, 24-39.

Moran, P.A.P., 1950. Notes on Continuous Stochastic Phenomena. Biometrika, 37, 17-23.

Ng, A., 2000. Volatility Spillover Effects from Japan and the US to the Pacific Basin. Journal of International Money and Finance, 19, 207-233.

Novo, A., 2003. Contagious Currency Crises: A Spatial Probit Approach. Banco de Portugal, Department of Economic Research.

Pericoli, M., and Sbracia, M., 2003. A Primer on Financial Contagion. Journal of Economic Surveys, 17, 571-608.

Pirinsky, C., and Wang, Q., 2006. Does Corporate Headquarters Location Matter for Stock Returns? The Journal of Finance, 61, 1991-2015.

Rigobon, R., 2002. International Financial: Theory and Evidence in Evolution. The Research Foundation of the Association for Investment Management and Research ${ }^{\mathrm{TM}}$.

Rittler, D., 2011. Price discovery and volatility spillovers in the European Union emissions trading scheme: a high-frequency analysis. Journal of Banking \& Finance, 36, 74-785.

Sokal, R.R., and Oden, N.L., 1978. Spatial autocorrelation in biology 1. Methodology. Biological Journal of the Linnean Society, 10, 199-228.

Villar, O., and Vayá, E. 2005. Financial Contagion between Economies: an Exploratory Spatial Analysis. Estudios de economía Aplicada, 23, 151-165.

White, H., Kim, T.H., and Manganelli, S., 2015. VAR for VaR: Measuring tail dependence using multivariate regression quantiles. Journal of Economics, 187, 169-188.

Worthington, A., and Higgs, H., 2004. Transmission of equity returns and volatility in Asian developed and emerging markets: a multivariate GARCH analysis. International Journal of Finance and Economics, 9, 71-80. 


\section{Tables}

Table 1. Countries included in the sample

\begin{tabular}{cccc}
\hline \multicolumn{2}{c}{ DEVELOPED MARKETS } & \multicolumn{2}{c}{ EMERGING MARKETS } \\
\hline \hline US & United States & MA & Morocco \\
JP & Japan & LK & Sri Lanka \\
DE & Germany & PK & Pakistan \\
GB & United Kingdom & IN & India \\
AU & Australia & CN & China \\
FR & France & BR & Brazil \\
IT & Italy & ZA & South Africa \\
SG & Singapore & ID & Indonesia \\
CA & Canada & MY & Malaysia \\
ES & Spain & MX & Mexico \\
CH & Switzerland & RU & Russian Federation \\
HK & Hong Kong & AR & Argentina \\
NL & Netherlands & CO & Colombia \\
SE & Sweden & CZ & Czech Republic \\
AT & Austria & HU & Hungary \\
BE & Belgium & TH & Thailand \\
FI & Finland & TR & Turkey \\
NZ & New Zealand & CL & Chile \\
NO & Norway & EG & Egypt \\
PT & Portugal & PE & Peru \\
DK & Denmark & PL & Poland \\
IE & Ireland & KR & Republic of Korea \\
IL & Israel & & \\
\hline & & & \\
\hline
\end{tabular}

Note: Data from Datastream International. 


\section{Table 2. Structural Breaks in Risk Synchronization}

\begin{tabular}{ccc}
\hline & MULTIPLE BREAKPOINT GLOBAL TEST \\
\hline \hline Index & Number of Breaks & Dates \\
\cline { 2 - 3 } & UDmax / WDmax & $4 / 30 / 1998,4 / 20 / 2011$ \\
Global-geographical & $1 / 2$ & $12 / 04 / 2001,11 / 17 / 2011$ \\
Global-economic & $2 / 2$ & \\
\hline
\end{tabular}

Note: Trimming 0.15, Max. breaks 5, Sign. Lev. 0.05. We perform recursive regressions on the following model: $\mathfrak{J}_{t}^{e}=\alpha_{0}+\varepsilon_{t}$, changing the definition of the left-hand side index: global-geographical, globaleconomic index. We use the methodology proposed by Bai and Perron (2002) and their corrected critical values to test the null of no-breaks. UDmax and WDmax are the equally weighted and the weighted versions of the double maximum tests proposed by Bai and Perron (2002). 
Table 3. Descriptive statistics of the indices based on the structural breaks detected

\begin{tabular}{cccc}
\hline \multicolumn{4}{c}{ GLOBAL-GEOGRAPHICAL INDEX} \\
\hline \multirow{3}{*}{ Mean } & Jan 95-Apr 98 & Apr 98-Apr 11 & Apr 11-Jul 15 \\
Median & 0.017 & 0.008 & 0.019 \\
Variance & 0.013 & 0.005 & 0.012 \\
Skewness & 0.001 & 0.001 & 0.002 \\
Kurtosis & 0.790 & 0.558 & 1.347 \\
& 1.423 & 1.394 & 2.668 \\
\hline \multirow{4}{*}{ Mean } & Jan $\mathbf{A L}$-ECONOMIC INDEX 01 & Dec 01-Nov 11 & Nov 11-Jul 15 \\
Median & -0.012 & -0.023 & -0.007 \\
Variance & -0.016 & -0.025 & -0.009 \\
Skewness & 0.003 & 0.002 & 0.003 \\
Kurtosis & 0.596 & 0.395 & 0.387 \\
\hline
\end{tabular}

Note: These are descriptive statistics of our indices after dividing the sample according to the date breaks detected using Bai and Perron's methodology (2002). 
Table 4. Global Risk Synchronization and Crises

\begin{tabular}{lc}
\hline & $\mathfrak{J}_{t}^{e}$ (Global Index) \\
\hline \hline Constant & $-0.0180^{* * *}$ \\
& $(0.0010)$ \\
Asian Crisis & 0.0041 \\
& $(0.0027)$ \\
European Debt Crisis & $0.0076^{* * *}$ \\
& $(0.0020)$ \\
Dotcom Crisis & $0.0050^{*}$ \\
& $(0.0027)$ \\
Subprime Crisis & $-0.0059^{* * *}$ \\
& $(0.0023)$ \\
\hline
\end{tabular}

Note: We perform regressions of the global index based on economic distances against dummy variables for the crises. The dates of the crises are taken from the IMF and the NBER webpages as follows - Asian Crisis: Jul 7, 1997-Dec 31, 1998; Dotcom Crisis: Mar 10, 2000-Nov 1, 2001; Subprime Crisis: Aug 9, 2007-Jun 1, 2009; and Euro Debt Crisis: Jun 1, 2010-Jun 2, 2014. We report the coefficients of the four dummy variables for the crises in each case, along with the standard errors. * means significant at $90 \%, * * 95 \%$ and $* * * 99 \%$ confidence levels. Heteroscedasticity and autocorrelation consistent variance-covariance (HAC) matrices are used to calculate standard errors in each case. 


\section{Figures}

Figure 1. Maps of Relative Risk in the Global Stock Markets

Figure 1(a): December 12, 1995

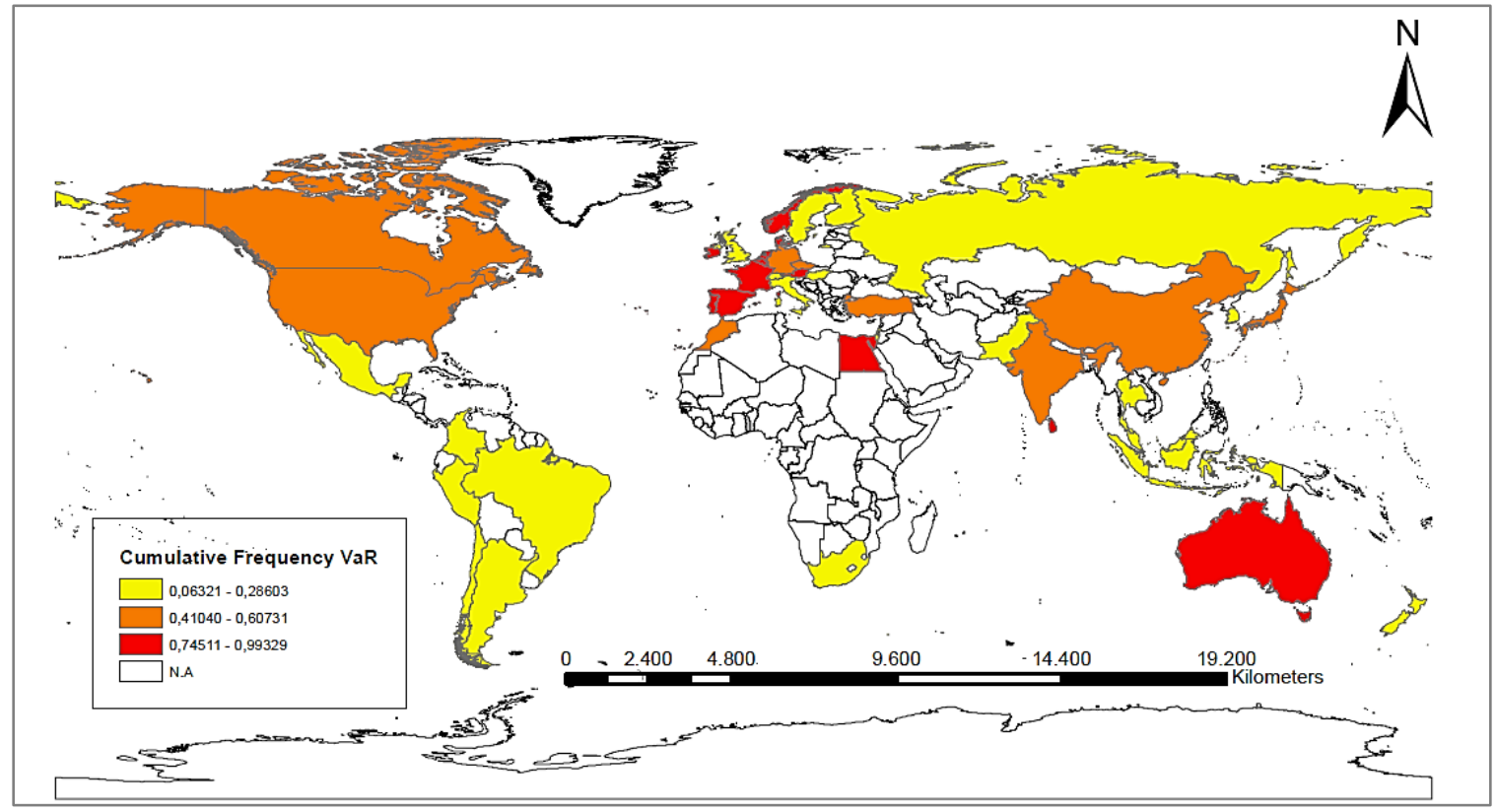

Figure 1(b): April 23, 2013

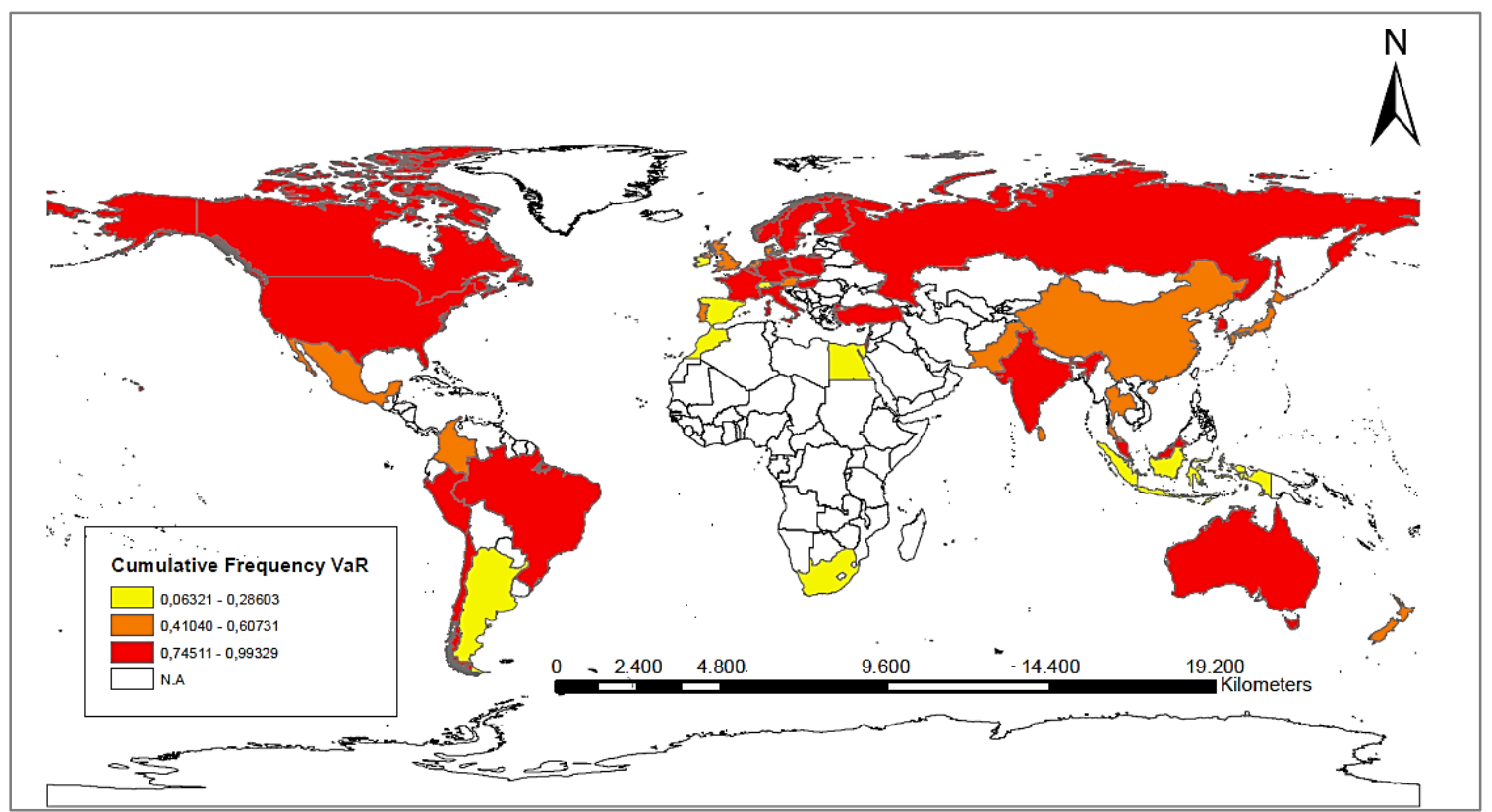


Figure 1(c): September 23, 2008

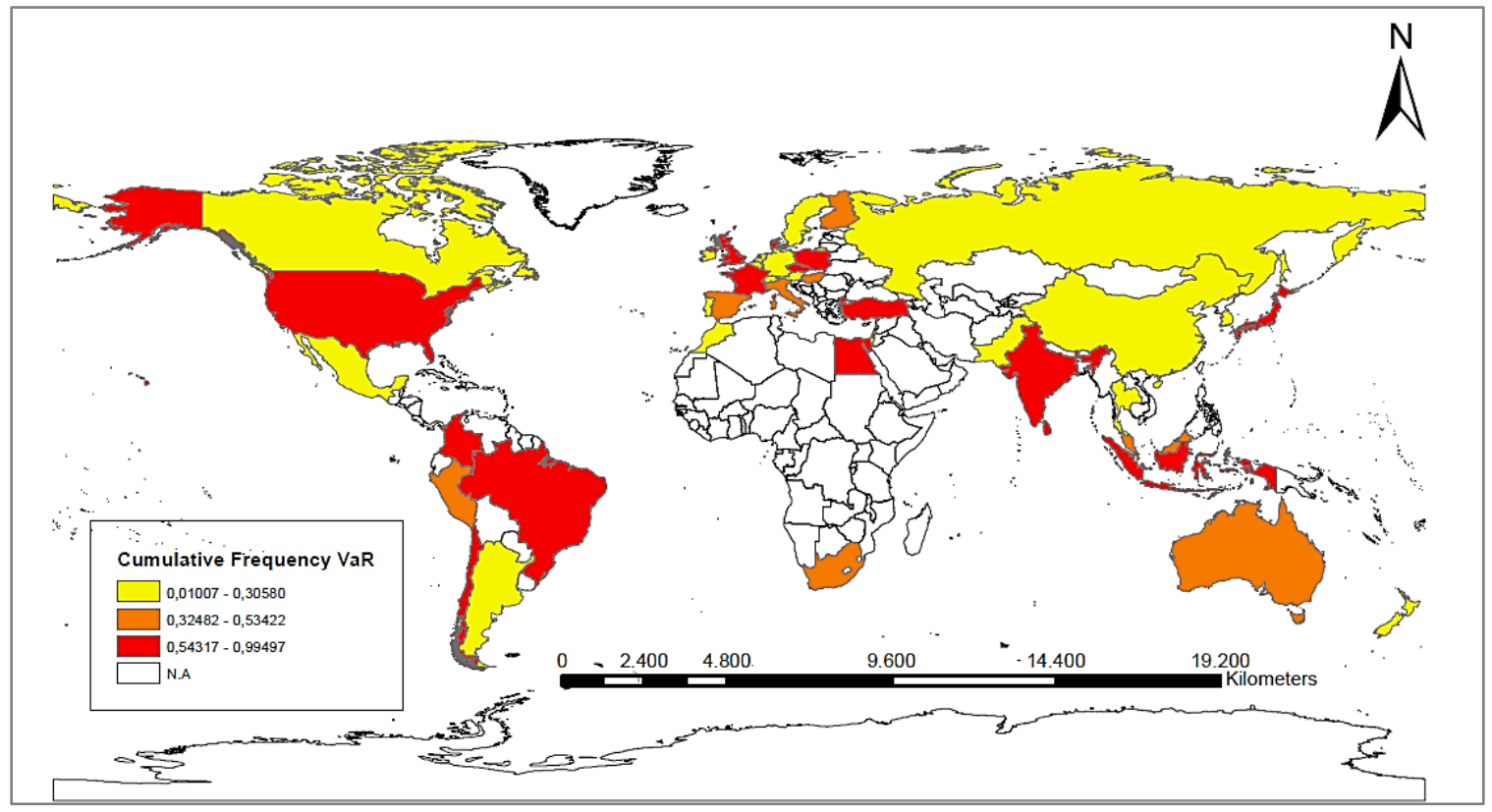

Note: Yellow areas correspond to low levels of risk (up to the 33rd percentile of the sample on a specific day).

Orange areas correspond to medium levels of risk (between the 33rd and 66th percentiles) and red areas correspond to high levels of risk (above the 66th percentile). 


\section{Figure 2. Spatial Autocorrelation Patterns}

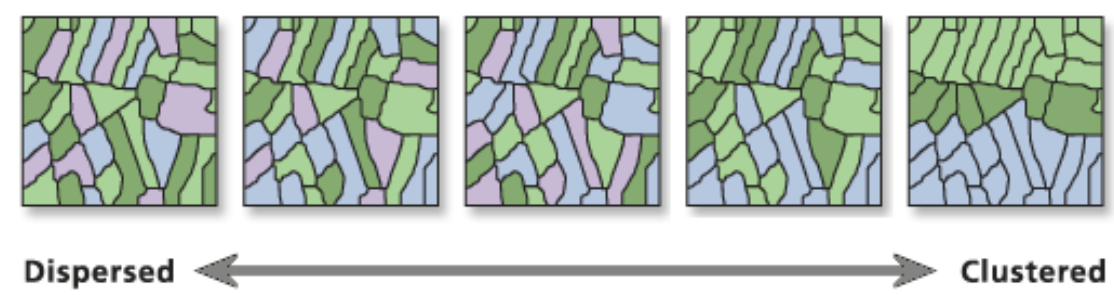

Note: Moran's Index ranges from -1 (dispersed, perfect negative spatial autocorrelation) to 1 (clustered, perfectly positive spatial autocorrelation). 
Figure 3. VaRs estimated from January 2, 1995 to July 23, 2015

Figure 3(a). Developed Markets

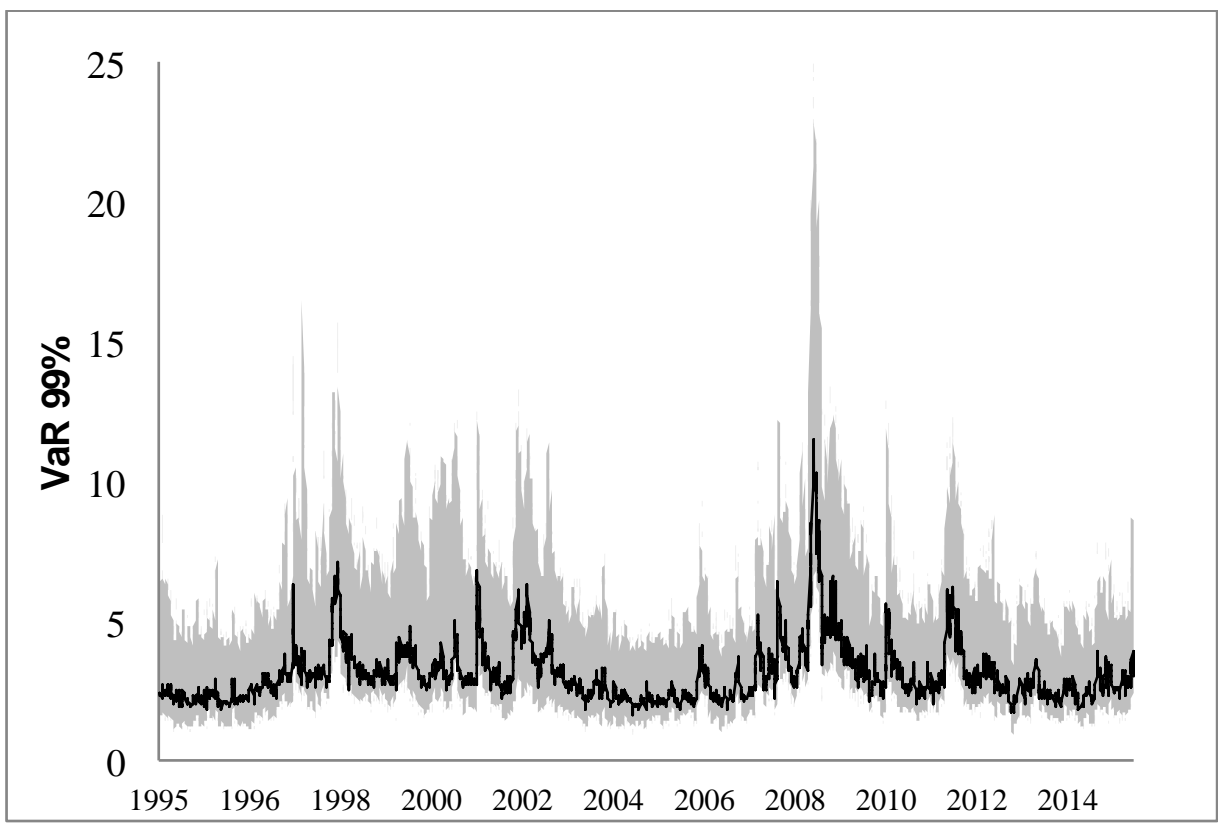

Figure 3(b). Emerging Markets

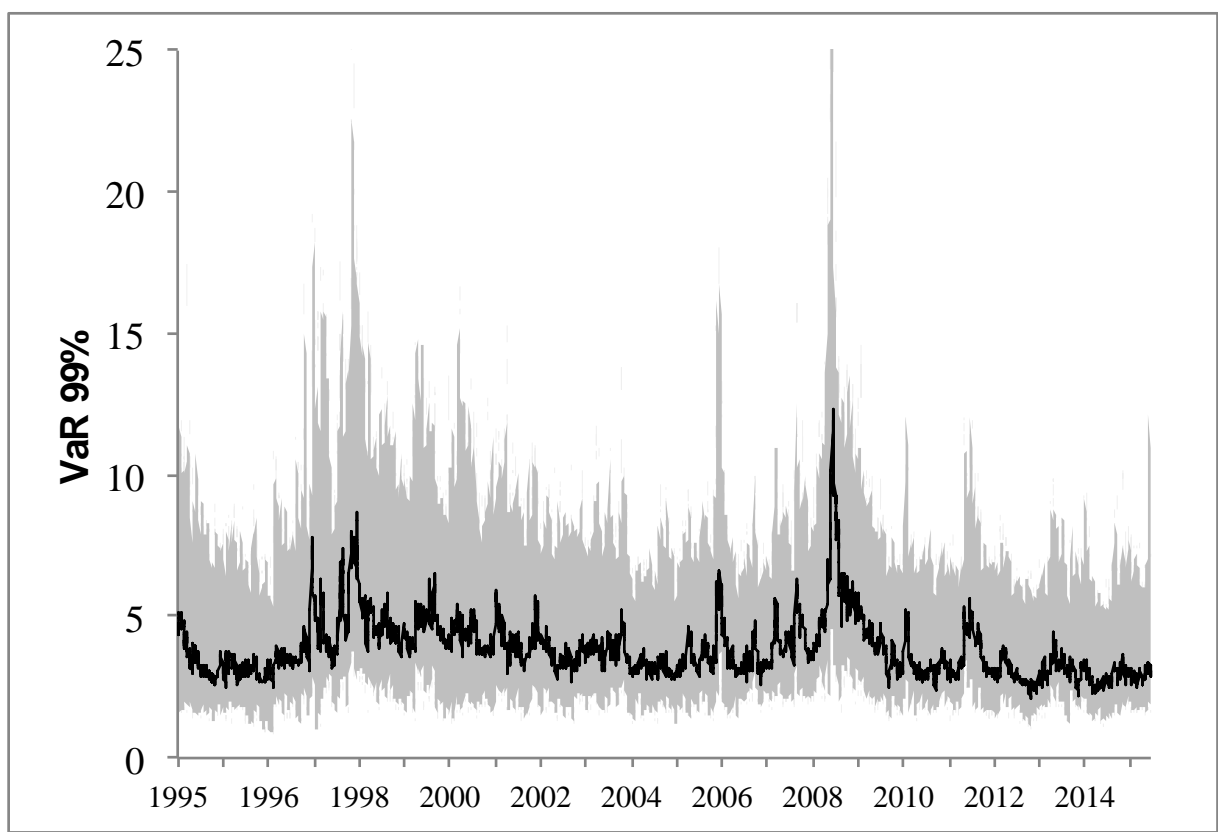

Note: In Figure 3(a) we present the median (solid line) of VaRs for the developed markets in our sample, together with the $5^{\text {th }}$ and the $95^{\text {th }}$ percentiles (shaded area). In Figure 3(b), we present the same statistics for emerging markets. 
Figure 4. VaRs estimated with the whole sample

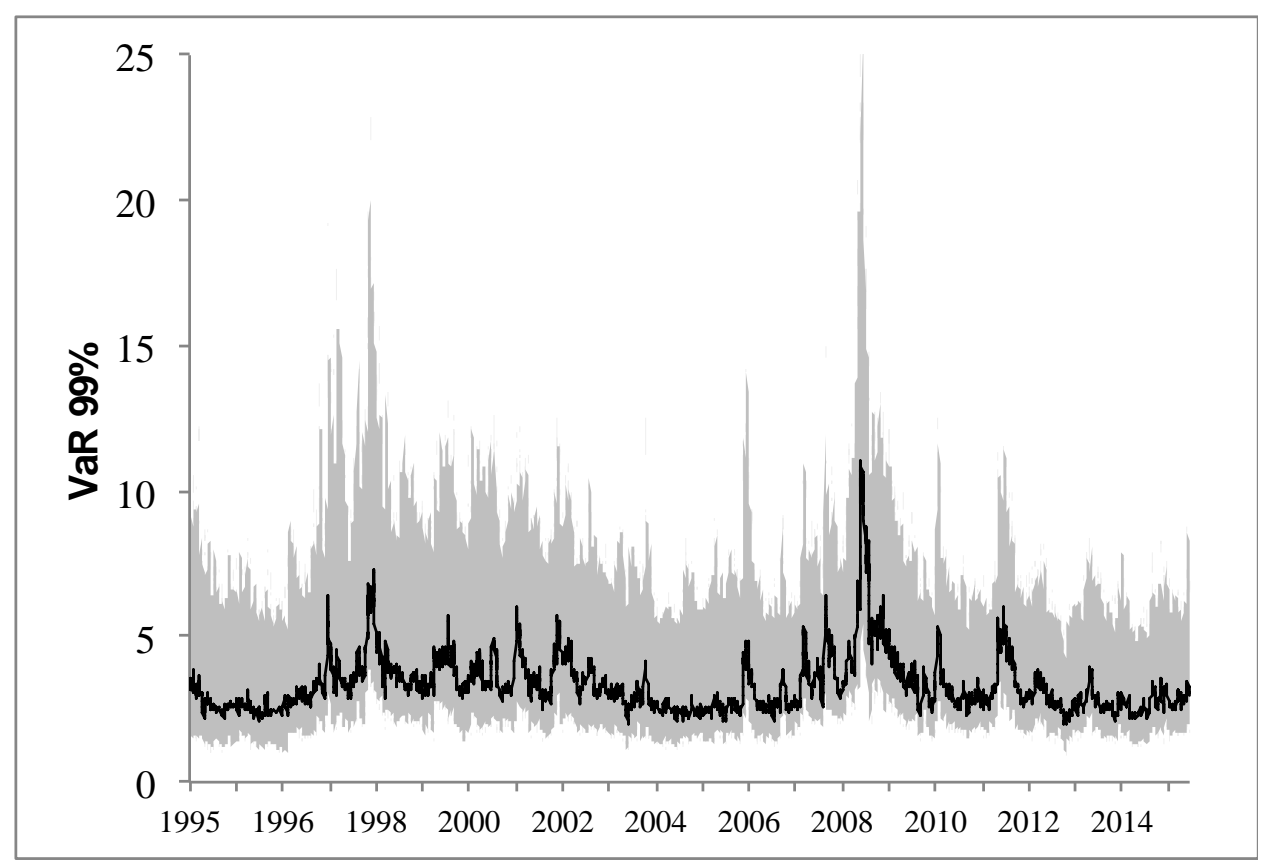

Note: We present the median (solid line) of VaRs for the whole sample, together with the $5^{\text {th }}$ and the $95^{\text {th }}$ percentiles (shaded area). 
Figure 5. VaRs of US and Chinese Markets

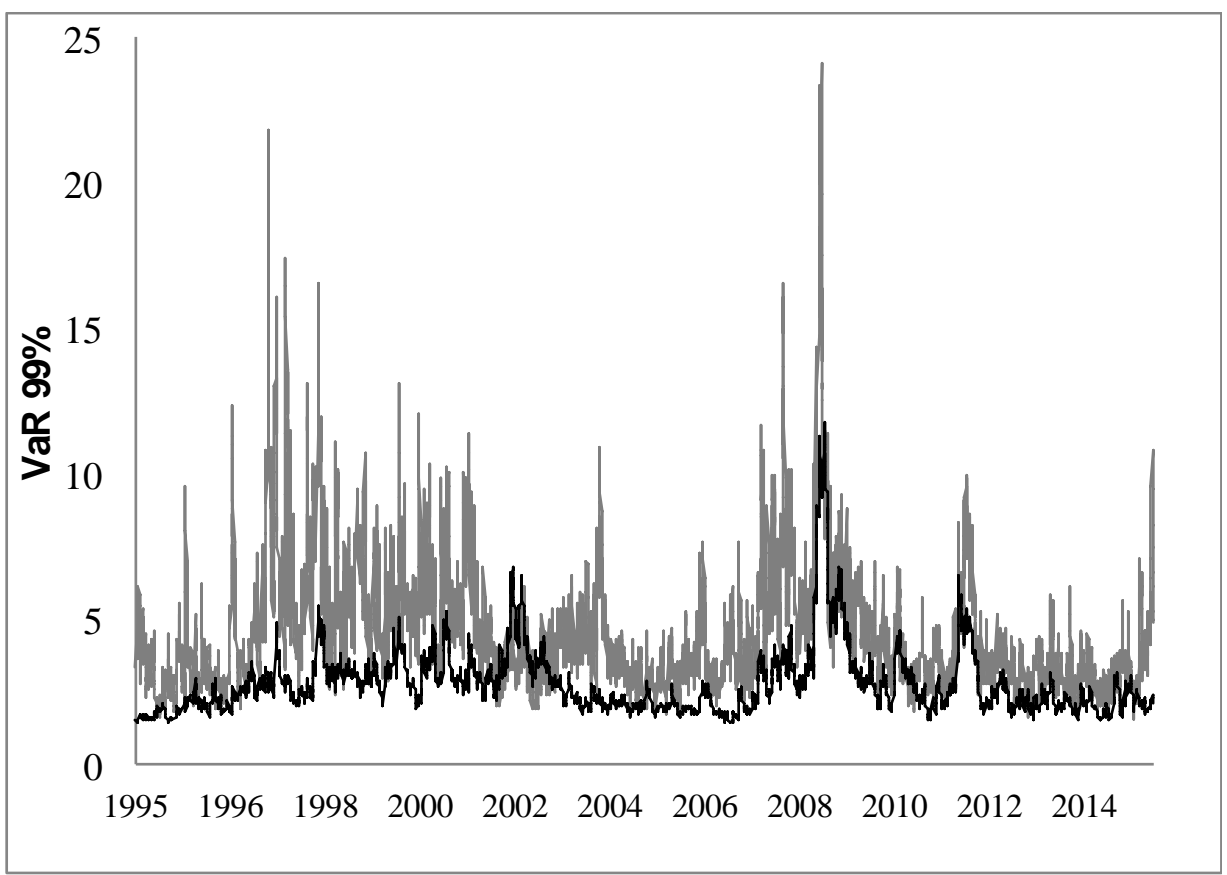

Note: VaRs at the 99\% confidence level for the US (bottom) and Chinese (top) markets from January 2, 1995 to July 23, 2015. 
Figure 6. Global Indices of Risk Synchronization, 1995-2015

Figure 6(a). Index using Geographical Distances

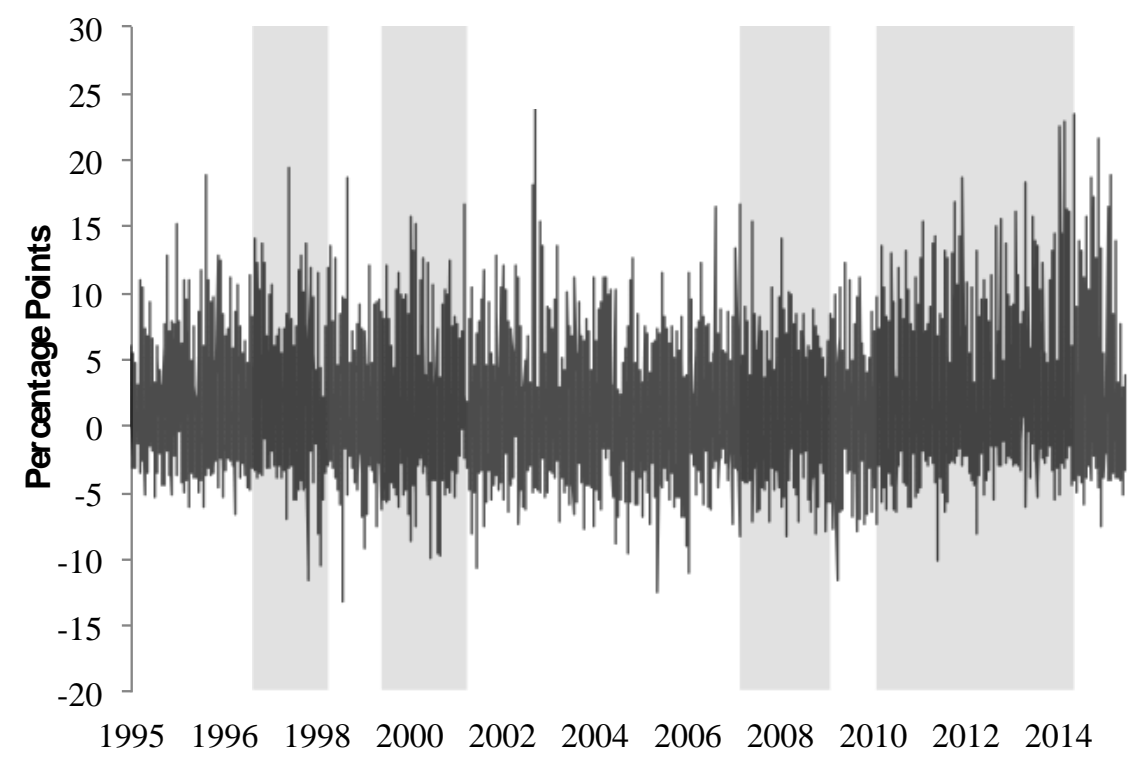

Figure 6(b). Index using Economic Distances

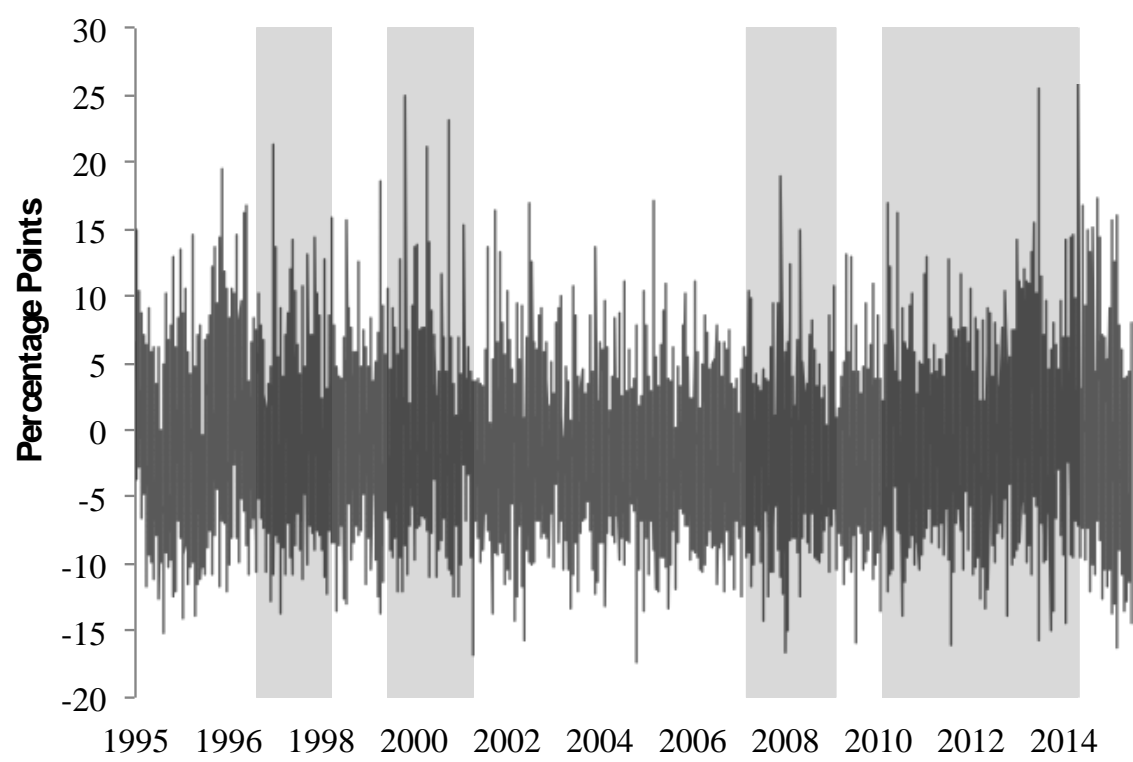

Note: The figure shows two versions of our global index of risk synchronization: the first [Figure 6(a)] constructed using geographical distances as weights in the spatial correlation, the second [Figure 6(b)] using economic distances. That is, we use the ratio bilateral-total exports and imports between country $i$ and country $j$ during a year, divided by total exports and imports of country $i$ during the same year. Notice that the index has a daily frequency because, despite the annual frequency of trade data, we have daily estimations of market risk for each country. 